\title{
Leaders
}

\section{A physically active lifestyle-public health's best buy?}

Times have changed. Many people spend most of their working time in the office, sitting behind computer terminals, PCs or laptops. Death is no longer from a mono-causal, infectious disease, but by multi-causal chronic diseases. Lifestyle factors, such as smoking, excessive alcohol intake, nutrition (for example, a too high intake of dietary fat or an excessive intake of polysaturated fatty acids, or both) and physical inactivity, play an important part in the aetiology of such chronic diseases, like coronary heart disease (CHD), hypercholesterolaemia, hypertension, stroke, non-insulin dependent diabetes mellitus (NIDDM), and certain forms of cancer. The first three factors are considered "classic" independent risk factors for multi-causal chronic disease. The role of physical inactivity as an independent lifestyle risk factor has been the subject of debate and controversy. This debate seems, however, to have come to an end with the publication of consensus statements ${ }^{1-3}$ and policy documents ${ }^{4-6}$ on the health benefits of a physically active lifestyle .

Not only will the individual person's health benefit from a reduced risk of the chronic diseases mentioned above but the public health status of a nation will benefit tremendously from a physically active lifestyle. The public health burden of a sedentary lifestyle can be quantified by calculating the population attributable risk (PAR) of such a lifestyle. PAR is an estimate of the proportion of the public health burden caused by a particular risk factor, for example, a sedentary lifestyle. By calculating PAR we may estimate the proportion of deaths from chronic diseases (CHD, NIDDM, cancer, etc) that would not occur if everyone in a population was sufficiently physically active. ${ }^{7}$ To calculate PAR, we need to know the relative risk (as a measure of the strength of the relation between a risk factor and the public health burden) and the prevalence of the risk factor. The "true" relative risk is constant because it is biologically determined and will therefore not change, even though estimates of relative risk may change because of improvement of scientific measurement. ${ }^{7}$ Consequently changes in PAR are highly dependent on changes in prevalence and not on changes in relative risk. Based on available information on both relative mortality risks and prevalences of a sedentary lifestyle Powell and Blair ${ }^{7}$ estimated the PAR of sedentary living for mortality from $\mathrm{CHD}$, colon cancer, and diabetes mellitus to be $35 \%, 32 \%$, and $35 \%$ respectively, meaning that $35 \%$ of the CHD deaths, $32 \%$ of the colon cancer deaths, and $35 \%$ of the diabetes mellitus deaths could be theoretically prevented if everyone was vigorously active. Recently in the Netherlands ${ }^{89}$ similar PAR calculations were made for chronic disease mortality, not only for a sedentary lifestyle, but also for other lifestyle (related) risk factors. These calculations were based on recent population data. For CHD the following PARs were calculated for men and women respectively: smoking $42 \%$ and $44 \%$, saturated fatty acid intake (exceeding $10 \%$ of total energy intake) $13 \%$ and $12 \%$, obesity (body mass index $>30) 13 \%$ and $15 \%$, and sedentary lifestyle $40 \%$ and $40 \%$. From these PARs it seems that for CHD mortality the public health burden caused by a sedentary lifestyle is at least of the same magnitude as the public health burden caused by smoking and about three times as great as the public health burden caused by obesity and the excess intake of saturated fatty acids, respectively. From a public health perspective it may be more appropriate to encourage a physically active lifestyle, second only to restriction of smoking habits, rather than to put emphasis on a further improvement of the dietary habits or on a reduction of body weight. Stimulating a physically active lifestyle has other related benefits; a physically active lifestyle (that is, regular exercise) helps to maintain body weight, leads to favourable dietary habits, and leads to a decline in the number of smokers. ${ }^{10}$ Knowing this it seems that stimulating a physically active lifestyle is public health's best buy.

If stimulating a physically active lifestyle is public health's best buy the next question is "how do we do that?" To answer this question one has to be aware of the determinants of physical activity behaviour. Many models are used to explain health related physical activity behaviour. In general these models include three sets of determinants: (1) knowledge and attitude, (2) social influence, and (3) barriers and self efficacy. ${ }^{11}$ Knowledge about, and attitudes towards, a physically active lifestyle seem to be sufficiently present in the general population. ${ }^{10}$ It therefore seems that stimulating a physically active lifestyle should predominantly be a matter of favourable changing social influence, influencing a person's self efficacy in a positive way, and breaking down the barriers that withhold people from being physically active. Dealing with this variety of physical activity determinants requires different preventative strategies and approaches, varying from mass media educational campaigns to political activism to change our society's system. Health care personnel should play an important part in getting more people more active and in this respect a promising approach (the PACE $=$ Physician-based Assesment and Counseling for Exercise approach) is thus based on the stages of change model. ${ }^{12}$ This model describes the changes that need to take place for a more physically active lifestyle. The PACE approach aims at overcoming barriers to counsel patients about physical activity behaviour for them to become physically more active. In pilot projects PACE programmes have proved to be both feasible ${ }^{13}$ and effective. ${ }^{14}$ From a public health standpoint further implementations and evaluation of PACE-like projects deserve wide attention within the common (para-)medical practice.

Finally, an argument brought up regularly against promoting physical activity is the risk of injury and the direct and indirect cost to society. In a recent macroeconomic analysis, however, on information derived from a representative sample of the Dutch population, the health benefits of physically active lifestyle (in terms of a reduced use of the health care system and a reduction of sick leave from work because of better health) outweigh the negative effects (in terms of cost of medical treatment and sick leave compensation) caused by sports injuries sustained. ${ }^{15}$ In this study this positive macro-economic balance in favour of a physically active lifestyle increases with increasing age.

To conclude, no time to waste, everybody should become more active now. It is everyone's concern.

WILLEM VAN MECHELEN

Institute for Research in Extramural Medicine and Department of Social Medicine, Faculty of Medicine, Vrije Universiteit, van der Boechorststraat 7, NL-1081 BT Amsterdam, the Netherlands 
1 Anonymous. Exercise for health. WHO/FIMS Committee on Physical Activity for Health. Bull World Health Organ 1995;733:135-6.

2 Pate RR, Pratt M, Blair SN, Haskell WL, Macera CA, Bouchard C, et al. Physical activity and public health: A recommendation from the Centers for Disease Control and Prevention and the American College of Sports Medicine. $\mathcal{F} A M A$ 1995;273:402-7

3 NIH Consensus development panel on physical activity and cardiovascular health. Physical activity and cardiovascular health. $¥ A M A$ 1996;276:241-6. 4 Killoran AJ, Fentem P, Caspersen CJ. Moving on. International perspectives on promoting phyical activity. London: Health Education Authority, 1994.

5 Anonymous. Recommendation no $R$ (95) 17 of the Committee of Ministers to the Member States on the significance of Sport for Society. Council of Europe. Strasbourg: CDDS (95) 58, 1995: 8-10.

6 US Physical activity and health; a report of the surgeon general. Atlanta GA: US Department of Health and Human Services, CDC, National Center for Disease Control and Prevention, USA, 1996.

7 Powell KE, Blair SN. The public health burden of sedentary living habits: theoretical but realistic estimates. Med Sci Sports Exerc 1994;26:851-6.

8 Ruwaard D, Kramers PGN, eds. Volksgezondheid Toekomst Verkenning. Den Haag: SDU, 1993.
9 Ruwaard D, Kramers PGN, eds. Volksgezondheid Toekomst Verkenning 1997. De som der delen. Utrecht: Elsevier/De Tijdstroom, 1997

10 Vuori I and Fentem P. Health, position paper. In: Vuori I, Fentem P, Svoboda B, Patriksson G, Andreff W, Weber W, eds. The significance of sport for society. Strasburg: Council of Europe Press, 1995: 11-90.

11 van Mechelen W. Can running injuries be effectively prevented? Sports Med 1995;19:161-5.

12 DiProchaska JO, Markus BH. The transtheoretical model: applications to exercise. In: Dishman RK, ed. Advances in exercise adherence. Champaign, Ill: Human Kinetics, 1994: 161-80.

13 Long BJ, Calfas KJ, Wooten W, Sallis JF, Patrick K, Goldstein M, et al. A multisite field test of the acceptability of physical activity counseling in primary care. Am f Prev Med 1996;12:73-81.

14 Calfas KJ, Long BJ, Sallis JF, Wooten W, Pratt M, Patrick K. A controlled trial of physician counselling to promote the adoption of phsyical activity. Prev Med 1996;25:225-33.

15 Stam PJA, Hildebrandt VH, Backx FJG, Velthuijsen JW. Sportief bewegen en gezondheidsaspecten: een verkennende studie naar kosten en baten. Amsterdam: SEO, 1996.

\section{The United Kingdom Diploma in Sport and Exercise Medicine}

On 15 September this year, the Academy of Medical Royal Colleges convened to consider, among other things, a draft proposal from the Intercollegiate Academic Board of Sport and Exercise Medicine. The board was quite specific about the inclusion of the word "exercise" in their proposal. This was accepted, putting in place the first diploma in sport medicine to be recognised throughout the United Kingdom and by all the medical Royal Colleges, ending what has been more than two years of arguing over who had the right to do what and with whom.

The first licensing body of medical graduates in the United Kingdom to offer a diploma in sports medicine was the Society of Apothecaries of London who had entry regulations in place as early as 1989. The Scottish Colleges (Surgeons and Physicians, Glasgow and Surgeons, Edinburgh and Physicians, Edinburgh) followed a year later. Of the two, the Society of Apothecaries had much the more stringent entry qualifications, demanding at least four years clinical practice and completion of a 20 week full time course in sports medicine or the equivalent part time course, or three full time courses of one weekend each together with two years full clinical sports medicine experience. Also acceptable was four years of full time sports medicine experience or a degree in sports medicine from a UK university.

By comparison, entry qualifications for the diploma Membership of the Royal College of Physicians UK, (a minimum of two and a half years postgraduate clinical experience of which at least 12 months must have been spent in the care of emergency medical patients, either adults or children, the latter post having been held within five years before the date of the examinations,) would seem to be less demanding.

Candidates for the UK Diploma in Sports Medicine must have engaged in the study of their profession for not less than two years after obtaining full registration with the General Medical Council and will be required to produce evidence of active participation in sports medicine.

These regulations may well change but it should not be assumed that the UK Diploma exam is any more easy (or difficult) than was the Apothecaries'. Indeed, any graduate who does not have at least three to four years "hands on" clinical experience in sports medicine and a Certificate of Advanced Life Support would be very unwise to present him or herself for examination. This comprises a two hour multiple choice and one hour short answer theoretical paper, followed by a practical examination to test core skills (such as cardiopulmonary resuscitation) to assess response to injury scenarios and first aid. Holders of other UK diplomas or degrees in sport and exercise medicine are likely to be exempt the first part of the exam, but all will be tested on their practical ability.

Other parties declaring an interest on the Intercollegiate Academic Board represent very diverse specialties. They include the following Royal Colleges; General Practitioners, Ophthalmologists, Paediatrics and Child Health, Pathologists, Physicians of London, Physicians of Edinburgh, Physicians and Surgeons of Glasgow, Surgeons of Edinburgh and Radiologists. Also represented are the Faculties of Dental Surgery, Occupational Medicine, and Public Health Medicine. Among all these, however, it must be said that those with the keenest clinical interest are the primary care doctors, physicians in clinical disciplines, and orthopaedic surgeons.

With training in sports medicine in the United States of America and Europe so well advanced, it is difficult to understand why the Colleges in England took so long to follow the Apothecaries' lead. Perhaps it was that they genuinely failed to realise the importance of sport and exercise in promoting the Health of the Nation. They certainly overlooked a lucrative source of income, because within months of the Diploma going live many of the professional sporting organisations in Britain were insisting that their medical officers in the field could show proof of training in sports medicine by producing their diplomas.

Setting up a UK Diploma has been only the first small step, the giant leap is going to be to establish specialist training because consultant physicians and orthopaedic surgeons with an additional specialist interest in sport and exercise medicine are going to form a very attractive acquisition for the cash starved NHS Trusts of the future. The Diploma has taken eight years to put in place, the question remains how many more years we are all going to have to wait for the CCST?

Chairman of Royal College of Physicians MARK HARRIES Consultant physician

Committee on Sport and Exercise Medicine 